\title{
Narrative review: clinical assessment of peripheral tissue perfusion in septic shock
}

\author{
Geoffroy Hariri ${ }^{1,2}$, Jérémie Joffre ${ }^{1,2}$, Guillaume Leblanc ${ }^{3,4}$, Michael Bonsey ${ }^{1}$, Jean-Remi Lavillegrand ${ }^{1,2}$, \\ Tomas Urbina', Bertrand Guidet ${ }^{1,2,5}$, Eric Maury ${ }^{1,2,5}$, Jan Bakker ${ }^{6,7,8,9}$ and Hafid Ait-Oufella $a^{1,2,10^{*}}$
}

\begin{abstract}
Sepsis is one of the main reasons for intensive care unit admission and is responsible for high morbidity and mortality. The usual hemodynamic targets for resuscitation of patients with septic shock use macro-hemodynamic parameters (hearth rate, mean arterial pressure, central venous pressure). However, persistent alterations of microcirculatory blood flow despite restoration of macro-hemodynamic parameters can lead to organ failure. This dissociation between macro- and microcirculatory compartments brings a need to assess end organs tissue perfusion in patients with septic shock. Traditional markers of tissue perfusion may not be readily available (lactate) or may take time to assess (urine output). The skin, an easily accessible organ, allows clinicians to quickly evaluate the peripheral tissue perfusion with noninvasive bedside parameters such as the skin temperatures gradient, the capillary refill time, the extent of mottling and the peripheral perfusion index.
\end{abstract}

Keywords: Septic shock, Microcirculation, Capillary refill time, Temperatures gradient, Peripheral perfusion index, Mottling, Skin

\section{Background}

International guidelines emphasized that fast identification, assessment and treatment combining early antibiotic therapy, fluid administration and vasopressor infusion are crucial steps in the management of septic shock. However, despite early management, mortality of patients with septic shock remains high [1]. A possible explanation may be the persistent tissue hypoperfusion despite restoration of macro-hemodynamic parameters.

The usual hemodynamic targets for resuscitation of patients with septic shock use macro-hemodynamic parameters (heart rate, mean arterial pressure, central venous pressure). However, persistent alterations of microcirculatory blood flow despite restoration of macro-hemodynamic parameters can lead to organ failure. In a meta-analysis of 252 patients, De Backer et al. [2] showed that microcirculatory perfusion alterations

\footnotetext{
*Correspondence: hafid.aitoufella@aphp.fr

1 Service de réanimation médicale, Assistance Publique-Hôpitaux de Paris (AP-HP), Hôpital Saint-Antoine, 184 rue du Faubourg Saint-Antoine, 75571 Paris Cedex 12, France

Full list of author information is available at the end of the article
}

predict mortality during serious infections, whereas mean arterial pressure or cardiac output did not. In critically ill patients, cardiac output optimization using increasing doses of dobutamine did not improve microvascular blood flow in the sublingual area [3, 4]. In another study, modulating mean arterial pressure by increasing norepinephrine dose had variable unpredictable effects on microcirculatory flow, which occasionally worsened $[5,6]$. This dissociation between macro- and microcirculatory compartments, defined by Ince as «a loss of hemodynamic coherence» [7], brings a need to assess end organs tissue perfusion in patients with septic shock and to develop tools to analyze microcirculatory blood flow [8]. The direct identification of severe microcirculatory alterations remains difficult at bedside. Traditional markers of tissue perfusion may not be readily available (lactate) or may take time to assess (urine output). The skin, an easily accessible organ, allows clinicians to quickly evaluate the peripheral tissue perfusion with noninvasive bedside parameters such as the skin temperatures gradient, the capillary refill time, the extent of mottling and the peripheral perfusion index. 
The aim of this review is to evaluate whether peripheral tissue perfusion assessment in septic patients could be helpful in evaluating organ failure severity and to screen patients at high risk of mortality. Finally, we analyze available data regarding implementation of peripheral perfusion evaluation in sepsis management.

\section{Skin as a tool for the evaluation of the microcirculation and tissue perfusion}

The skin provides important information in patients with septic shock. As a visible and easily accessible organ, the skin allows simple observation of local microcirculatory perfusion through skin temperature alterations (skin temperature gradient), perfusion (capillary refill time) and color (mottling). The pathophysiology of these clinical disorders has not been investigated in depth, but several authors assume that the main driven mechanism of reduced blood flow is local vasoconstriction mediated by sympathetic neuroactivation [8]. Additional mechanisms could participate to impair microvascular blood flow (Fig. 1) $[9,10]$ such as local endothelial dysfunction [11, 12] (Fig. 2), leukocyte adhesion, platelet activation and fibrin deposition [13]. These clinical, noninvasive, easyto-use, parameters are attractive tools to follow microcirculatory perfusion in patients with acute circulatory failure $[14,15]$. In 2014, several European experts recommended to integrate abnormal skin perfusion parameters in the definition and treatment of shock [16].

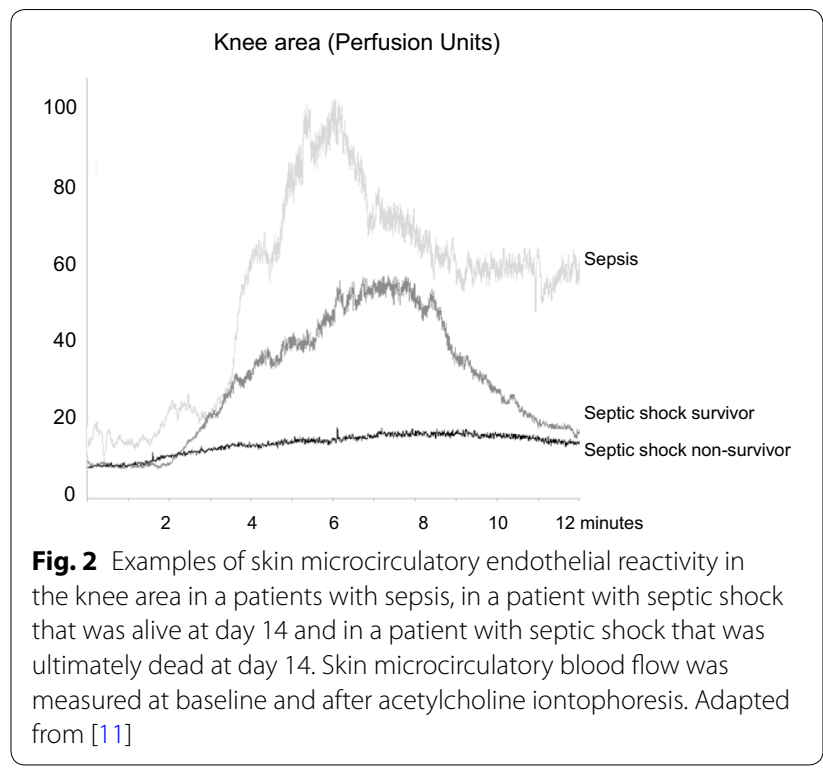

Subjective assessment of peripheral skin temperature may be a valuable tool in the evaluation of patients with septic shock. Eighty years ago, Ebert et al. [17] described the skin of septic shock patients as being "pale, often sweaty». Altemeier et al. [18] then noticed that a moist and cold skin was a factor of worse prognosis in patients with septic shock. Cold hands and feet, and abnormal skin color are the first clinical signs that developed

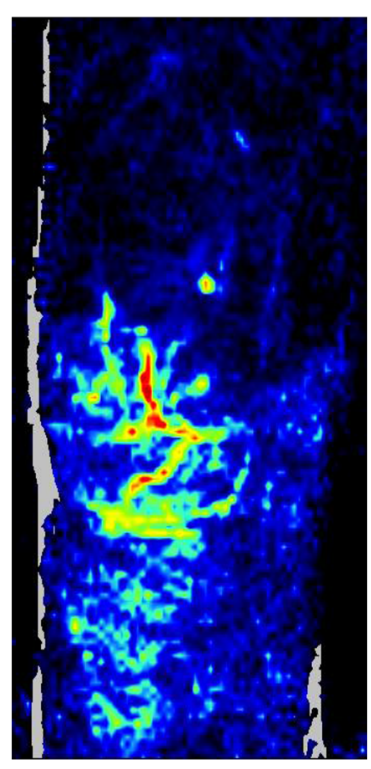

Stage 0

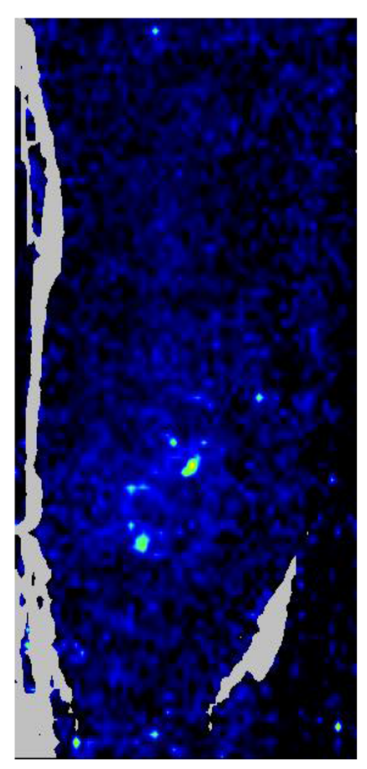

Stage 3

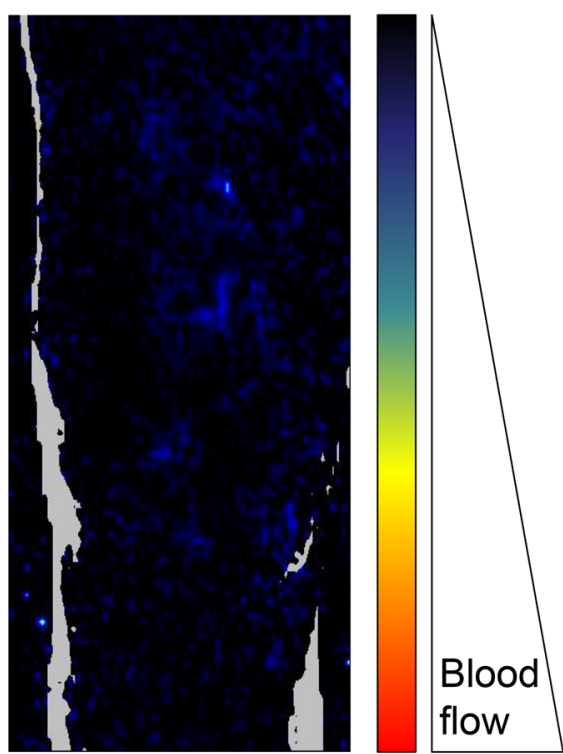

Stage 5

Fig. 1 Examples of skin microvascular perfusion evaluation using laser Doppler imaging in the knee area according to the mottling score. Skin perfusion decreases when mottling score worsens. Adapted from [9] 
in meningococcal disease in children [19]. In a cohort of 264 surgical ICU patients, patients with cold skin on extremities and knees had significantly lower central venous saturation and higher lactate level as compared to patients with normal skin temperature $(4.7 \pm 1.5$ vs $2.2 \pm 1.6 \mathrm{mmol} / \mathrm{L}, p<0.05)$ [20]. In a prospective cohort study of 50 critically ill patients with circulatory dysfunction, including 26 patients with septic shock, Lima et al. [21] observed that patients with cold skin on the extremities had a higher rate of organ failure at $48 \mathrm{~h}$ after resuscitation as compared to patients with normal skin temperature.

However, skin temperature gradients may be more accurate in the evaluation of patients with septic shock. Several studies investigated quantitative temperature gradients in critically ill patients, particularly between peripheral and ambient temperatures [22], central and peripheral body temperatures [23] and finger and forearm skin temperatures [24]. Temperature gradients do not correlate with cardiac output $[22,25,26]$ but are predictive of both organ failure severity and worse outcome. Joly et al. [22] measured toe-to-ambient temperature gradients $3 \mathrm{~h}$ after admission in a mixed population of critically ill patients, and non-survivors had a mean toe-ambient temperature gradient of $0.9{ }^{\circ} \mathrm{C}$, whereas survivors had a gradient of $3.4{ }^{\circ} \mathrm{C}$. Normalization of central-peripheral temperature gradients $\left(<7^{\circ} \mathrm{C}\right)$ within the 6 first hours of resuscitation predicted correction of hyperlactatemia in septic shock patients [27]. In a recent study including 103 septic patients, Bourcier et al. [28] reported higher central-to-toe temperature gradients and lower toe-to-ambient temperature gradients in patients with septic shock, compared to patients with sepsis. Moreover, a rise in the toe-to-ambient temperature gradient was independently associated with decreased ICU mortality (OR $0.7[0.5,0.9]$ per $\left.{ }^{\circ} \mathrm{C}, p<0.001\right)$.

Finger-to-forearm skin and toe-to-ambient temperature gradients are more accurate tools that could be used in every patient without previous hypothermia, including patients with dark skin, providing quantitative information with good reproducibility (Table 1, Fig. 3).

\section{Capillary refill time}

The capillary refill time (CRT) measures the amount of time necessary for the skin to return to baseline color after applying a pressure on a soft tissue (generally finger tip). The CRT gives important information on skin perfusion and microcirculatory status but does not reflect cardiac output $[25,29]$. Visual measurement of CRT associated with other clinical signs (tachycardia, mucosal dryness, etc.) helps to diagnose dehydration in children [30]. In acute pathologies, such as gastro-intestinal infections or malaria [31], CRT represents an attractive and easy-to-use tool for clinicians in the initial screening of severely ill patients [32]. Inter-rater variability of CRT was weak in non-trained physicians [33], but is better in centers expert in tissue perfusion evaluation [34], especially in the knee area [35]. Standardization of finger-tip pressure (i.e., How long? How strong the applied pressure?) might improve CRT reproducibility. Ait-Oufella et al. [35] obtained good inter-rater concordance by "applying a firm pressure for $15 \mathrm{~s}$. The pressure applied was just enough to remove the blood at the finger tip of the physician's nail illustrated by appearance of a thin white distal crescent (blanching) under the nail."

Capillary refill time measurement correlates with the pulsatility index, a surrogate ultrasound-derived parameter that reflects vascular tone of visceral organs in septic shock patients [36]. CRT is an interesting tool to assess the severity of an acute illness. In the intensive care unit, Lima et al. [21] reported an association between a prolonged CRT ( $>4.5 \mathrm{~s}$ on the index finger) and hyperlactatemia and a higher SOFA score. In septic shock patients, a prolonged CRT $6 \mathrm{~h}$ after resuscitation has been shown to be predictive of 14-day mortality, with an Area Under Curve (AUC) of $84 \%$ for a measure on the index finger, and $90 \%$ for a measure on the knee. A 2.4-second threshold value on the index finger predicted mortality with an $82 \%$ sensitivity (95\% CI [60-95]) and a $73 \%$ specificity (95\% CI [56-86]). On the knee, a threshold value of $4.9 \mathrm{~s}$ predicted 14-day mortality with an $82 \%$ sensitivity (95\% CI [60-95]) and an 84\% specificity (95\% CI [68-94]) [35].

Overall, when used as a qualitative variable (prolonged or not), CRT is a reliable triage tool to identify critically ill patients at risk of negative outcome. Quantitative measurement of CRT should be mainly used by trained physicians in patients with non-dark skin (Table 1, Fig. 3).

\section{Mottling}

Mottling, a characteristic discoloration of the skin following reduced skin blood flow [9], is taught as a marker of shock, but its clinical relevance has been poorly investigated until recent years. A significant relationship between mottling extension and visceral organ vascular tone has been reported suggesting that mottling could reflect gut, liver spleen and kidney hypoperfusion [36].

To assess the predictive value of mottling in critically ill patients with severe infections, a semi-quantitative clinical score for mottling (ranging from 0 to 5), based on the extension of these purple patches from the patella toward the periphery, has been developed and validated with an excellent inter-observer reproducibility [37] (Kappa 0.87\% (CI 95\% [0.72-0.97]) (Fig. 4). Mottling score reliably reflects organ failure severity in patients with sepsis or septic shock and helps to 


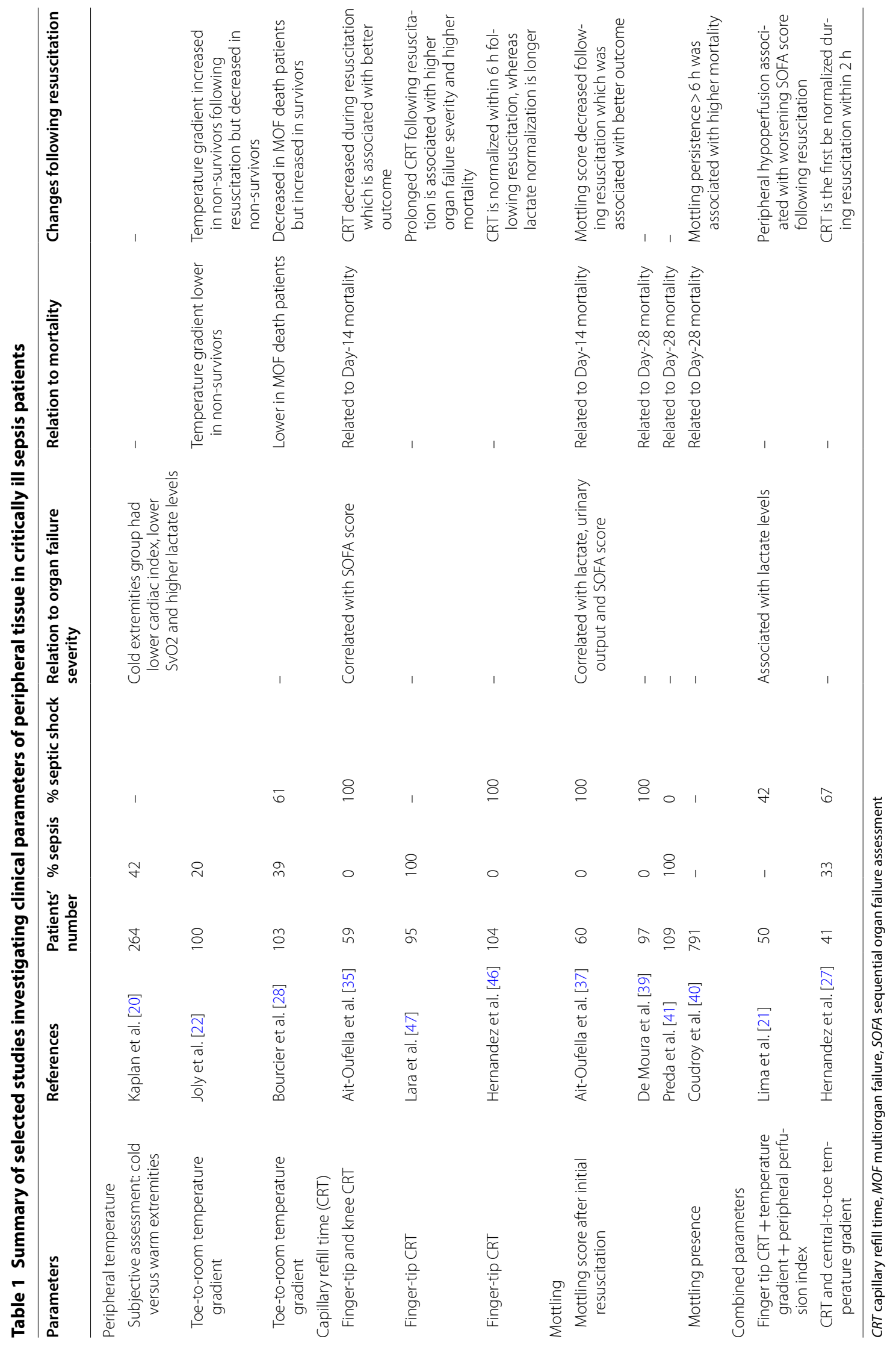




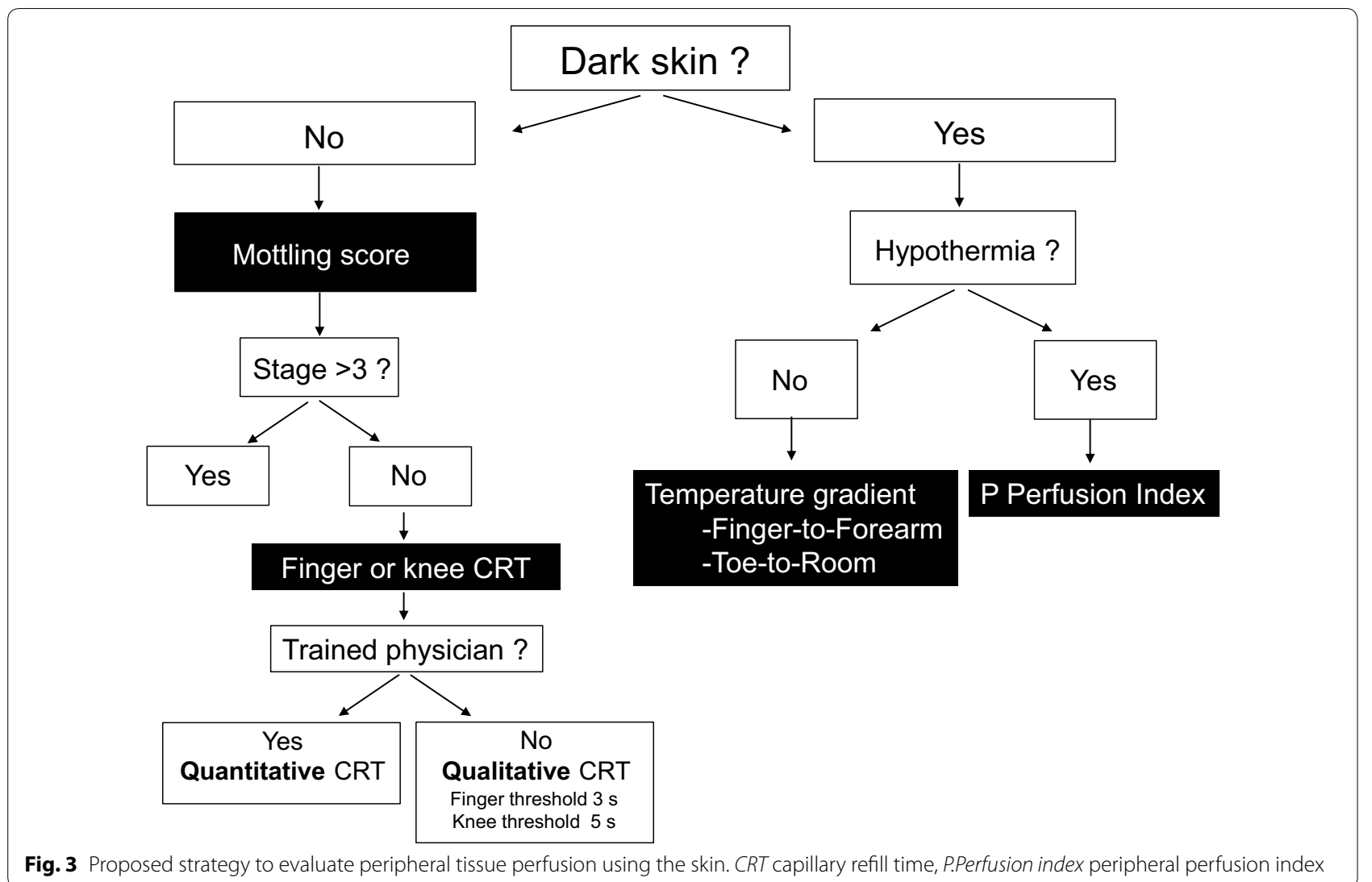

identify critically ill patients with worse outcome. In a study including septic shock patients, the mottling score at $6 \mathrm{~h}$ after resuscitation was predictive of death at day 14 (odds radio [OR] 16, CI 95\% 4-81, for stages $2-3$; vs 74 , CI $95 \% 11-1568$, for stages $4-5$ ). Mortality occurred within $12-24 \mathrm{~h}$ for stages $4-5$, within $24-72 \mathrm{~h}$ for stages $2-3$ and later than $72 \mathrm{~h}$ for the rare deaths for stages $0-1$ (Kaplan-Meier charts, $p<0.0001$ ). In the same study, cardiac output and blood pressure were not associated with mortality at day 14 , confirming the disparity between microcirculatory and macrocirculatory parameters [37]. These results were confirmed in cirrhotic patients with septic shock [38]. In addition, in mottling groups $\leq 3$, knee CRT improved patient discrimination according to their outcome, with nonsurvivors presenting a significantly higher knee CRT [35]. Another South American study confirmed these results in septic shock patients. Mortality rate at day 28 was $100 \%$ when the mottling score was higher or equal to stage $4,77 \%$ for stages 2 and 3 , and $45 \%$ for stages 1 or lower [39]. Prognostic value of mottling was also reported in unselected ICU patients: Persistent $(>6 \mathrm{~h}$ ) mottling extending over the knee (>stage 2 ) was an independent risk factor for mortality (OR 3.29, 95\% CI 2.08-5.19; $p<0.0001$ ) [40]. Finally, Preda et al.
[41] found the good predictive value of the mottling score for mortality at day 28 in patients with sepsis not receiving vasopressors.

In summary, mottling score is a reliable semi-quantitative tool that reflects organ failure severity in nonselected septic patients with or without vasopressors and is helpful to identify critically ill patients with pejorative outcome and also to monitor changes during resuscitation. In patients with mottling score ranging from 0 to 3, knee CRT measurement could be associated with improving risk stratification (Table 1, Fig. 3).

\section{Peripheral perfusion index}

Peripheral perfusion index is defined as the difference between the pulsatile and non-pulsatile portion of pulse wave, measured by plethysmography. Peripheral perfusion index (PPI) gives information on peripheral vascular tonus by the pulsatility, decreasing in vasoconstriction and raising in vasodilation [42]. Peripheral perfusion index is an early predictor of central hypovolemia [43]. In a prospective observational study in an emergency department, PPI was not significantly different between patients admitted to the hospital and patients discharged from the emergency department suggesting that it could not be used as a triage tool [44]. However, in critically 
a

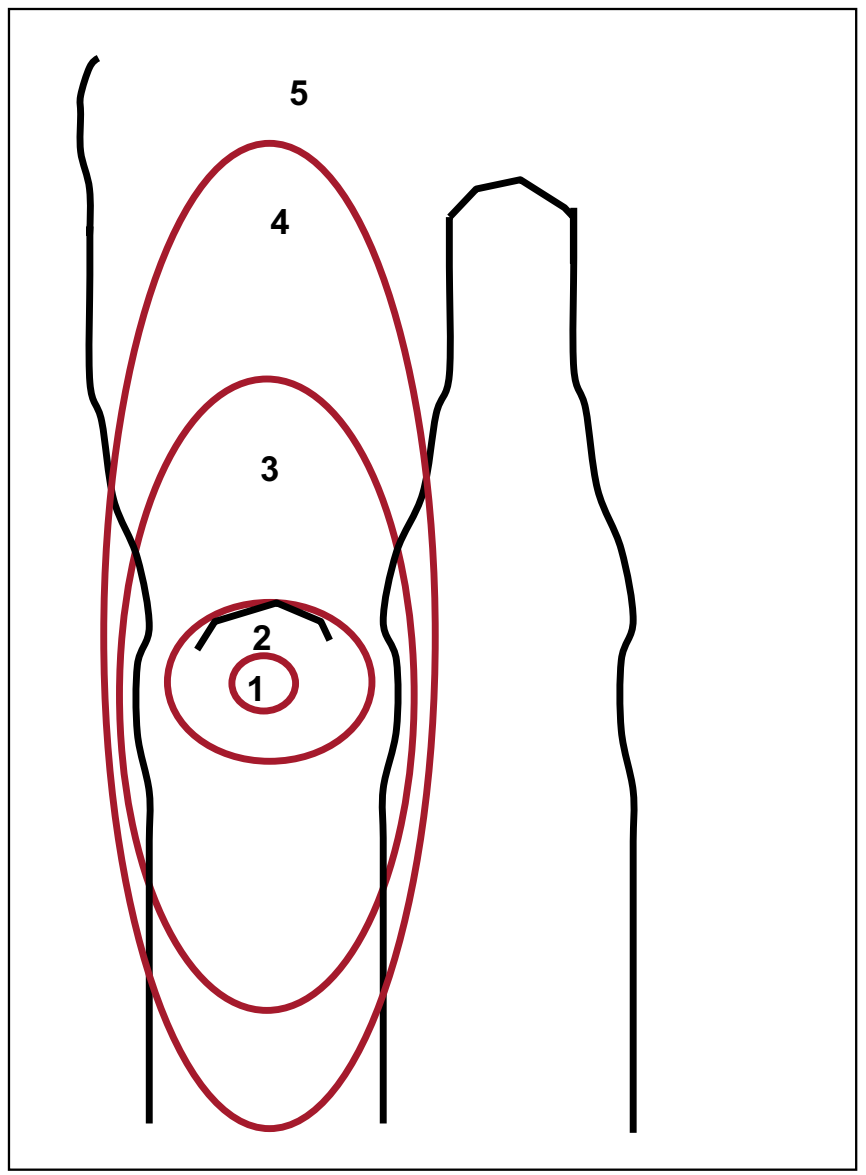

b

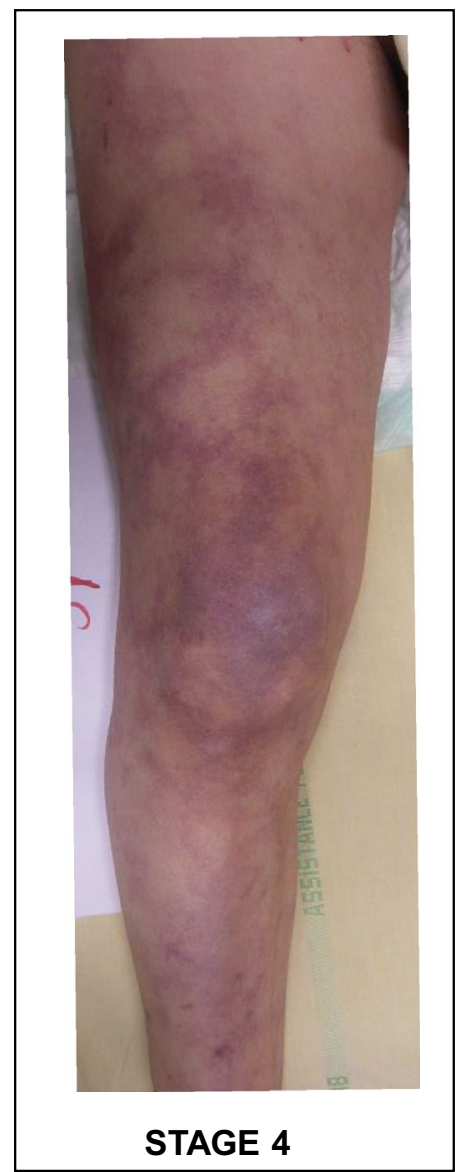

Fig. 4 a The mottling score, ranging from 0 to 5, is based on skin mottling area extension on legs. Score 0 represents no mottling, score 1 represents small mottling area (coin size) localized to the center of the knee, score 2 represents mottling area not exceeding the superior edge of the knee cap, score 3 represents mottling area not exceeding the middle thigh, score 4 represents mottling area not exceeding the fold of the groin and score 5 otherwise. b Example of mottling score 5. Adapted from [37]

ill patients, PPI is significantly lower in patients with a peripheral perfusion alteration $(0.7$ vs $2.3, p<0.01)$ [21]. He et al. [45] showed that the PPI is altered in septic shock patients, as compared to control subjects in postoperative scheduled surgery. Moreover, in the same study, the PPI was significantly lower in non-survivors. With a 0.20 cutoff value, PPI was predictive of ICU mortality with an AUC of 84\% (69-96), a sensitivity of $65 \%$ and a specificity of $92 \%$.

\section{Discussion}

Abnormal skin perfusion evaluation and resuscitation

Despite some differences between micro and macrovascular compartments, it would be over-simplifying and possibly wrong to completely separate these two vascular compartments. In the study by Ait-Oufella et al. [37] focusing on mottling, global hemodynamic improvement within the first hours following resuscitation, based on blood volume optimization and catecholamine use, was associated with mottling improvement. Patients whose mottling score improved through the first 6-hour resuscitation had a good prognosis, whereas those whose score was stable or even worsened had a poor prognosis (14-day mortality: $23 \%$ vs $88 \%, p<0.001)$. Finger-tip CRT is also quickly normalized in septic shock patients within 2-6 h after resuscitation, whereas hyperlactatemia requires longer time to recover $[27,46]$. Interestingly, patients in whom CRT did not recover after fluid infusion had pejorative outcome [47]. Altogether, these studies suggest that peripheral tissue perfusion could be used as triage tool at the early steps of sepsis management at admission and after fluid infusion. The ongoing ANDROMEDA-SHOCK trial aims to compare two resuscitation strategies during the first hours of sepsis 
treatment on 28-day mortality, one based on CRT measurement and the other on arterial lactate clearance [48]. During ICU stay, evaluation of peripheral perfusion could also be helpful. A "proof-of-concept» study has been done comparing a volume expansion strategy based on peripheral perfusion, clinical parameter assessment, to a classical strategy based on mean arterial pressure, central venous pressure and cardiac index. Peripheral perfusion was assessed through CRT, index-forearm temperature gradient, peripheral perfusion index, and $\mathrm{StO} 2$. The resuscitation strategy based on clinical tissue perfusion assessment led to a reduction in fluid therapy volume in the first $72 \mathrm{~h}(7565 \pm 982 \mathrm{~mL}$ vs. $10,028 \pm 941 \mathrm{~mL}$, $p=0.08)$ and to a reduction in hospital length of stay (16 [5-28] vs. 43 [8-45] days, $p<0.05$ ) [49]. A task force of six international experts with extensive bedside experience recently proposed to integrate peripheral tissue perfusion tools in risk stratification and management of septic patients in resource-limited intensive care units, especially CRT, mottling score and temperature gradients [50].

As bedside evaluation of tissue perfusion using the skin improves risk stratification in patients with sepsis, there is a possibility that it could be used as a tool to guide resuscitation. Lavillegrand et al. [51] reported that a mild arterial hypotension (MAP between 55 and $65 \mathrm{mmHg}$ ) could be safely tolerated in patients without any sign of hypoperfusion. Such «personalized» management requires close monitoring (in an ICU) but may decrease the use of invasive devices and vasopressors, both having potential side effects. Conversely, patients with markers of tissue hypoperfusion require rapid ICU transfer, and also, we hypothesized that they should be good candidate for therapeutic approaches targeting microcirculation for resuscitation in the future. For example, nitroglycerin infusion had no beneficial effect in unselected sepsis patients [52] but improved peripheral perfusion in selected patients with prolonged CRT and/or increased finger-tip-to-forearm skin gradient temperatures [53]. Ilomedin has been also recently proposed as a rescue therapy in sepsis shock with refractory tissue hypoperfusion [54] and will be tested soon in a prospective randomized multicenter trial (I-MICRO NCT03788837). In the future, it is important to evaluate whether drugs targeting the microcirculation could improve outcome of selected patients with persistent peripheral hypoperfusion despite initial resuscitation [55]. The first results of ANDROMEDA-SHOCK, an international multicenter trial recently completed, support that a tissue perfusionguided resuscitation is beneficial $[48,56]$. Indeed, Hernandez et al. [56] showed in septic shock adults that an early peripheral perfusion-targeted resuscitation, aiming at normalizing capillary refill time, was associated with less organ dysfunction at day 3 and a trend toward reduced 28-day mortality when compared to a lactatelevel-targeted therapeutic strategy.

\section{Limitations}

In this review, almost all data were obtained in smallsized monocenter observational studies and were performed by experts in tissue perfusion evaluation, suggesting potential biases. In addition, no published multicenter randomized trial is available showing that the implementation of bedside tissue perfusion assessment improves septic patients management and in fine outcome. This narrative review did not provide strong recommendation regarding the use of tissue perfusion parameters in septic patients according to GRADE methodology but only proposed how and when to implement them.

\section{Conclusion}

In patients with septic shock, tissue microvascular hypoperfusion can be evaluated at bedside using indicators of skin perfusion. After initial resuscitation, these parameters are helpful in identifying patients with severe organ failure and at high risk of mortality. However, there is a need in the future to investigate these bedside tissue microvascular perfusion parameters as management targets for resuscitation in septic shock patients.

\section{Abbreviations \\ Cl: confidence interval; CRT: capillary refill time; ICU: intensive care unit; MAP: mean arterial pressure; NIRS: near-infrared spectroscopy; NO: nitric oxide; OR: odds ratio; PPI: peripheral perfusion index; SOFA: sequential organ failure assessment; SAPS II: Simplified Acute Physiologic Score II; ROC: receiver operat- ing characteristics.}

\section{Authors' contributions}

Drafting and critical revision of manuscript was done by all authors. All authors read and approved the final manuscript.

\footnotetext{
Author details

${ }^{1}$ Service de réanimation médicale, Assistance Publique-Hôpitaux de Paris (AP-HP), Hôpital Saint-Antoine, 184 rue du Faubourg Saint-Antoine, 75571 Paris Cedex 12, France. ${ }^{2}$ Sorbonne Université, Université Pierre-et-Marie Curie-Paris 6, Paris, France. ${ }^{3}$ Division of Critical Care Medicine, Department of Anesthesiology and Critical Care Medicine, Université Laval, Québec City, QC, Canada. ${ }^{4}$ Population Health and Optimal Health Practices Research Unit (Trauma Emergency - Critical Care Medicine), Centre de recherche du CHU de Québec - Université Laval, Université Laval, Québec City, QC, Canada. ${ }^{5}$ Inserm U1136, Paris 75012, France. ${ }^{6}$ Department Intensive Care Adults, Erasmus MC University Medical Center, Rotterdam, The Netherlands. ${ }^{7}$ Department of Pulmonology and Critical Care, Columbia University Medical Center, New York, USA.

${ }^{8}$ Department of Pulmonology and Critical Care, New York University Medical Center - Bellevue Hospital, New York, USA. ${ }^{9}$ Department of Intensive Care, Pontificia Universidad Católica de Chile, Santiago, Chile. ${ }^{10}$ Inserm U970, Centre de Recherche Cardiovasculaire de Paris (PARCC), Paris, France.
}

Acknowledgements

None. 


\section{Competing interests}

None.

\section{Availability of data and materials}

Not applicable.

\section{Consent for publication}

Not applicable.

Ethics approval and consent to participate

Not applicable.

\section{Source of funding}

None.

\section{Publisher's Note}

Springer Nature remains neutral with regard to jurisdictional claims in published maps and institutional affiliations.

Received: 7 January 2019 Accepted: 1 March 2019

Published online: 13 March 2019

\section{References}

1. Rhee C, Dantes R, Epstein L, Murphy DJ, Seymour CW, Iwashyna TJ, et al Incidence and trends of sepsis in US hospitals using clinical vs claims data, 2009-2014. JAMA. 2017;318(13):1241-9.

2. De Backer D, Donadello K, Sakr Y, Ospina-Tascon G, Salgado D, Scolletta $S$, et al. Microcirculatory alterations in patients with severe sepsis: impact of time of assessment and relationship with outcome. Crit Care Med. 2013;41(3):791-9.

3. De Backer D, Creteur J, Dubois MJ, Sakr Y, Koch M, Verdant C, et al. The effects of dobutamine on microcirculatory alterations in patients with septic shock are independent of its systemic effects. Crit Care Med. 2006;34(2):403-8

4. Hernandez G, Bruhn A, Luengo C, Regueira T, Kattan E, Fuentealba A, et al. Effects of dobutamine on systemic, regional and microcirculatory perfusion parameters in septic shock: a randomized, placebo-controlled, double-blind, crossover study. Intensive Care Med. 2013;39(8):1435-43.

5. Dubin A, Pozo MO, Casabella CA, Palizas F Jr, Murias G, Moseinco MC, et al. Increasing arterial blood pressure with norepinephrine does not improve microcirculatory blood flow: a prospective study. Crit Care. 2009;13(3):R92.

6. Thooft A, Favory R, Salgado DR, Taccone FS, Donadello K, De Backer D, et al. Effects of changes in arterial pressure on organ perfusion during septic shock. Crit Care. 2011;15(5):R222.

7. Ince $\mathrm{C}$. Hemodynamic coherence and the rationale for monitoring the microcirculation. Crit Care. 2015;19(Suppl 3):S8

8. Lima A, Bakker J. Noninvasive monitoring of peripheral perfusion. Intensive Care Med. 2005:31(10):1316-26.

9. Ait-Oufella H, Bourcier S, Alves M, Galbois A, Baudel JL, Margetis D, et al. Alteration of skin perfusion in mottling area during septic shock. Ann Intensive Care. 2013;3(1):31.

10. Ait-Oufella H, Bourcier S, Lehoux S, Guidet B. Microcirculatory disorders during septic shock. Curr Opin Crit Care. 2015;21(4):271-5.

11. Bourcier S, Joffre J, Dubee V, Preda G, Baudel JL, Bige N, et al. Marked regional endothelial dysfunction in mottled skin area in patients with severe infections. Crit Care. 2017;21(1):155.

12. Becker L, Prado K, Foppa M, Martinelli N, Aguiar C, Furian T, et al. Endothelial dysfunction assessed by brachial artery ultrasound in severe sepsis and septic shock. J Crit Care. 2012;27(3):316e9-14.

13. Ait-Oufella H, Maury E, Lehoux S, Guidet B, Offenstadt G. The endothelium: physiological functions and role in microcirculatory failure during severe sepsis. Intensive Care Med. 2010;36(8):1286-98.

14. Ait-Oufella $\mathrm{H}$, Bakker J. Understanding clinical signs of poor tissue perfusion during septic shock. Intensive Care Med. 2016;42(12):2070-2.

15. Lima A, Bakker J. Clinical assessment of peripheral circulation. Curr Opin Crit Care. 2015;21(3):226-31.
16. Cecconi M, De Backer D, Antonelli M, Beale R, Bakker J, Hofer C et al. Consensus on circulatory shock and hemodynamic monitoring. Task force of the European Society of Intensive Care Medicine. Intensive Care Med. 2014;40(12):1795-815.

17. Ebert RV, Stead EA. Circulatory failure in acute infections. J Clin Invest. 1941;20(6):671-9.

18. Altemeier WA, Cole W. Septic shock. Ann Surg. 1956;143(5):600-7.

19. Thompson MJ, Ninis N, Perera R, Mayon-White R, Phillips C, Bailey L, et al. Clinical recognition of meningococcal disease in children and adolescents. Lancet. 2006;367(9508):397-403.

20. Kaplan LJ, McPartland K, Santora TA, Trooskin SZ. Start with a subjective assessment of skin temperature to identify hypoperfusion in intensive care unit patients. J Trauma. 2001;50(4):620-7 (discussion 7-8).

21. Lima A, Jansen TC, van Bommel J, Ince C, Bakker J. The prognostic value of the subjective assessment of peripheral perfusion in critically ill patients. Crit Care Med. 2009:37(3):934-8

22. Joly HR, Weil MH. Temperature of the great toe as an indication of the severity of shock. Circulation. 1969:39(1):131-8.

23. Ibsen B. Treatment of shock with vasodilators measuring skin temperature on the big toe. Ten years' experience in 150 cases. Dis Chest. 1967;52(4):425-9

24. House JR, Tipton MJ. Using skin temperature gradients or skin heat flux measurements to determine thresholds of vasoconstriction and vasodilatation. Eur J Appl Physiol. 2002;88(1-2):141-5.

25. Bailey JM, Levy JH, Kopel MA, Tobia V, Grabenkort WR. Relationship between clinical evaluation of peripheral perfusion and global hemodynamics in adults after cardiac surgery. Crit Care Med. 1990;18(12):1353-6.

26. Vincent JL, Moraine JJ, van der Linden P. Toe temperature versus transcutaneous oxygen tension monitoring during acute circulatory failure. Intensive Care Med. 1988;14(1):64-8.

27. Hernandez G, Pedreros C, Veas E, Bruhn A, Romero C, Rovegno M, et al. Evolution of peripheral vs metabolic perfusion parameters during septic shock resuscitation.A clinical-physiologic study. J Crit Care. 2012;27(3):283-8.

28. Bourcier S, Pichereau C, Boelle PY, Nemlaghi S, Dubee V, Lejour G, et al. Toe-to-room temperature gradient correlates with tissue perfusion and predicts outcome in selected critically ill patients with severe infections. Ann Intensive Care. 2016;6(1):63.

29. Tibby SM, Hatherill M, Murdoch IA. Capillary refill and core-peripheral temperature gap as indicators of haemodynamic status in paediatric intensive care patients. Arch Dis Child. 1999;80(2):163-6.

30. Gorelick MH, Shaw KN, Murphy KO. Validity and reliability of clinical signs in the diagnosis of dehydration in children. Pediatrics. 1997;99(5):E6.

31. Evans JA, May J, Ansong D, Antwi S, Asafo-Adjei E, Nguah SB, et al. Capillary refill time as an independent prognostic indicator in severe and complicated malaria. J Pediatr. 2006;149(5):676-81.

32. Gove S, Tamburlini G, Molyneux E, Whitesell P, Campbell H. Development and technical basis of simplified guidelines for emergency triage assessment and treatment in developing countries. WHO Integrated Management of Childhood IIIness (IMCI) Referral Care Project. Arch Dis Child. 1999:81(6):473-7.

33. Alsma J, van Saase J, Nanayakkara PWB, Schouten W, Baten A, Bauer MP, et al. The power of flash mob research: conducting a nationwide observational clinical study on capillary refill time in a single day. Chest. 2017;151(5):1106-13.

34. van Genderen ME, Paauwe J, de Jonge J, van der Valk RJ, Lima A, Bakker $J$, et al. Clinical assessment of peripheral perfusion to predict postoperative complications after major abdominal surgery early: a prospective observational study in adults. Crit Care. 2014;18(3):R114.

35. Ait-Oufella H, Bige N, Boelle PY, Pichereau C, Alves M, Bertinchamp R, et al. Capillary refill time exploration during septic shock. Intensive Care Med. 2014:40(7):958-64.

36. Brunauer A, Kokofer A, Bataar O, Gradwohl-Matis I, Dankl D, Bakker J, et al. Changes in peripheral perfusion relate to visceral organ perfusion in early septic shock: a pilot study. J Crit Care. 2016;35:105-9.

37. Ait-Oufella H, Lemoinne S, Boelle PY, Galbois A, Baudel JL, Lemant J, et al. Mottling score predicts survival in septic shock. Intensive Care Med. 2011;37(5):801-7.

38. Galbois A, Bige N, Pichereau C, Boelle PY, Baudel JL, Bourcier S, et al. Exploration of skin perfusion in cirrhotic patients with septic shock. J Hepatol. 2015:62(3):549-55. 
39. de Moura EB, Amorim FF, da Cruz Santana AN, Kanhouche G, de Souza Godoy LG, de Jesus Almeida L, et al. Skin mottling score as a predictor of 28-day mortality in patients with septic shock. Intensive Care Med. 2016;42(3):479-80.

40. Coudroy R, Jamet A, Frat JP, Veinstein A, Chatellier D, Goudet V, et al. Incidence and impact of skin mottling over the knee and its duration on outcome in critically ill patients. Intensive Care Med. 2015;41(3):452-9.

41. Preda G, Bourcier S, Joffre J, Boelle PY, Dubee V, Baudel JL, et al. Mottling score is associated with 28-day mortality in critically ill patients with sepsis. Minerva Anestesiol. 2017;83(6):664-6.

42. Hales JR, Stephens FR, Fawcett AA, Daniel K, Sheahan J, Westerman RA, et al. Observations on a new non-invasive monitor of skin blood flow. Clin Exp Pharmacol Physiol. 1989;16(5):403-15.

43. van Genderen ME, Bartels SA, Lima A, Bezemer R, Ince C, Bakker J, et al. Peripheral perfusion index as an early predictor for central hypovolemia in awake healthy volunteers. Anesth Analg. 2013;116(2):351-6.

44. Oskay A, Eray O, Dinc SE, Aydin AG, Eken C. Prognosis of Critically ill patients in the ED and value of perfusion index measurement: a crosssectional study. Am J Emerg Med. 2015;33(8):1042-4.

45. He HW, Liu DW, Long Y, Wang XT. The peripheral perfusion index and transcutaneous oxygen challenge test are predictive of mortality in septic patients after resuscitation. Crit Care. 2013;17(3):R116.

46. Hernandez G, Luengo C, Bruhn A, Kattan E, Friedman G, Ospina-Tascon $G A$, et al. When to stop septic shock resuscitation: clues from a dynamic perfusion monitoring. Ann Intensive Care. 2014;4:30.

47. Lara B, Enberg L, Ortega M, Leon P, Kripper C, Aguilera P, et al. Capillary refill time during fluid resuscitation in patients with sepsis-related hyperlactatemia at the emergency department is related to mortality. PLoS ONE. 2017;12(11):e0188548.

48. Hernandez G, Cavalcanti AB, Ospina-Tascon G, Zampieri FG, Dubin A, Hurtado FJ, et al. Early goal-directed therapy using a physiological holistic view: the ANDROMEDA-SHOCK - a randomized controlled trial. Ann Intensive Care. 2018;8(1):52.

49. van Genderen ME, Engels N, van der Valk RJ, Lima A, Klijn E, Bakker J, et al. Early peripheral perfusion-guided fluid therapy in patients with septic shock. Am J Respir Crit Care Med. 2015;191(4):477-80.

50. Misango D, Pattnaik R, Baker T, Dunser MW, Dondorp AM, Schultz MJ, et al. Haemodynamic assessment and support in sepsis and septic shock in resource-limited settings. Trans R Soc Trop Med Hyg. 2017;111(11):483-9.

51. Lavillegrand JR, Dumas G, Bige N, Zafimahazo D, Guidet B, Maury E, et al. Should we treat mild hypotension in septic patients in the absence of peripheral tissue hypoperfusion? Intensive Care Med. 2018;44(9):1593-4.

52. Boerma EC, Koopmans M, Konijn A, Kaiferova K, Bakker AJ, van Roon EN, et al. Effects of nitroglycerin on sublingual microcirculatory blood flow in patients with severe sepsis/septic shock after a strict resuscitation protocol: a double-blind randomized placebo controlled trial. Crit Care Med. 2010;38(1):93-100.

53. Lima A, van Genderen ME, van Bommel J, Klijn E, Jansem T, Bakker J. Nitroglycerin reverts clinical manifestations of poor peripheral perfusion in patients with circulatory shock. Crit Care. 2014;18(3):R126.

54. Depret F, Sitbon A, Soussi S, De Tymowski C, Blet A, Fratani A, et al. Intravenous iloprost to recruit the microcirculation in septic shock patients? Intensive Care Med. 2018;44(1):121-2.

55. Legrand $M$, Ait-Oufella $H$, Ince C. Could resuscitation be based on microcirculation data? Yes. Intensive Care Med. 2018;44(6):944-6.

56. Hernandez G, Ospina-Tascon GA, Damiani LP, Estenssoro E, Dubin A, Hurtado J, et al. Effect of a resuscitation strategy targeting peripheral perfusion status vs serum lactate levels on 28-day mortality among patients with septic shock: the ANDROMEDA-SHOCK randomized clinical trial. JAMA. 2019;321(7):654-64.

\section{Submit your manuscript to a SpringerOpen ${ }^{\circ}$ journal and benefit from:}

- Convenient online submission

- Rigorous peer review

- Open access: articles freely available online

- High visibility within the field

- Retaining the copyright to your article

Submit your next manuscript at $\boldsymbol{\nabla}$ springeropen.com 